\title{
Awareness: potential toxicities of carbon nanotubes
}

\author{
Nico van Zandwijk ${ }^{1}$, Arthur L. Frank ${ }^{2}$ \\ ${ }^{1}$ Concord Clinical School/Sydney Medical School, Concord Repatriation General Hospital, Concord, Australia; ${ }^{2}$ Environmental and Occupational \\ Health, Dornsife School of Public Health of Drexel University, Philadelphia, PA, USA \\ Correspondence to: Nico van Zandwijk, MD, PhD, FRACP, FCCP. Professor Emeritus, Concord Clinical School/Sydney Medical School, Concord \\ Repatriation General Hospital, Hospital Road, Concord NSW 2139, Australia. Email: nico.vanzandwijk@sydney.edu.au.
}

Submitted Oct 08, 2019. Accepted for publication Oct 16, 2019.

doi: $10.21037 /$ tlcr.2019.12.05

View this article at: http://dx.doi.org/10.21037/tlcr.2019.12.05

Carbon nanotubes belong to a class of tiny tubular structures composed of carbon atoms. These carbon atoms are arranged in a honeycomb-type (nano)tube and their structure and the strength of the bonds between the atoms provide exceptional physicochemical properties. Carbon nanotubes consist of either single graphene cylinders [single-walled carbon nanotube (SWCNT)] with an outer diameter of 1-3 nm, or multiple graphene cylinders arranged in concentric layers [multi-walled carbon nanotube (MWCNT)] with diameters ranging from 10 to $200 \mathrm{~nm}$ and a length from a few hundreds of nano-meters to several tens of micro-meters. The unique physicochemical, mechanical (strength/stiffness), electrical, and thermal properties of carbon nanotubes have contributed to an increased use of these materials in the electronics, aerospace, computer, and pharmaceutical industries.

The shape of carbon nanotubes closely resembles asbestos (chrysotile and amphibole) fibers, known for their carcinogenic potential (1). Therefore, it comes not as a surprise that experimental studies carried out during the last 15 years confirm that carbon nanotubes are capable of eliciting chronic inflammation, granuloma formation, fibrosis and mesothelioma-like pathology in experimental animals. Today, two decades after the appearance of the first reports describing the synthesis of carbon nanotubes more than 2,000 citations appear in PubMed, when carbon nanotube and toxicity are used as search terms.

The reports published since the beginning of the 2000s can be summarized as follows: Inhalational studies reveal high bio-persistence of carbon nanotubes in the lungs of experimental animals giving rise to (chronic) inflammation, fibrosis, gene damage and tumor formation (2-7). The sequence of these events is roughly the same as noticed after inhalation of asbestos fibers and also the inflammation induced by carbon nanotubes has been found to be dependent on the length of the nanotube (8), a concept first put faith by Stanton (9).

In 2013, the US National Institute for Occupational Safety and Health (NIOSH) called for attention to the potential hazards of and recommended an exposure limit for carbon nanotubes: "DHHS (NIOSH) Publication. Current intelligence bulletin 65: occupational exposure to carbon nanotubes and nanofibers. CDC, 2013:145", doi: 10.26616/ NIOSHPUB2013145. Since 2016, the use of single-wall carbon nanotubes is guided by the European Union's Registration, Evaluation, Authorization and Restriction of Chemicals (REACH) regulations "REACH registration completed for single-wall carbon nanotubes", www.pcimag. com., PCI Mag, 16 October 2016. Carbon nanotubes are high on the priority list for IARC monographs (10) but it is evident that world-wide preventive measures have not yet been considered or taken.

When discussing preventive measures, it is vital to not only understand the pathophysiology of the carcinogenic processes that may occur after the inhalation of carbon nanotubes, but also to recognize that the latency period between exposure and occurrence of disease is likely to be of considerable length. The latency period between asbestos inhalation and occurrence of malignancy (mesothelioma/ lung cancer) ranges between 10 and 50 or more years and similar latency periods are foreseen when inhalation of carbon nanotubes is concerned (11).

Therefore, it is expected to take several decades before respiratory cancers will be noticed in people exposed to carbon nanotubes. This expectation reiterates the importance of adequate preventive measures and shows 
that we have already failed in making timely preventive recommendations.

It is obvious that any release of carbon nanotubes (in the air) during the production process should be avoided. Little is known about testing of carbon nanotubes containing materials before they are admitted to the market. Weathering of materials containing bonded asbestos has provided an example how toxic fibers can be released and cause disease. Therefore, establishing world-wide safety standards for carbon nanotubes should be regarded a first priority. The lack of protective measures to avoid the continuing inhalation of (asbestos and microparticle) contaminated air is daily practice in many developing countries and the failure to adopt adequate safety measures in a timely manner may create another time-bomb that is going to explode in about 30-40 years from now (12).

The lessons learned from the ongoing epidemic of asbestos-related diseases are grim and provide a good reason not to hesitate to take drastic measures to avoid the emergence of another epidemic of man-made disease.

\section{Acknowledgments}

None.

\section{Footnote}

Conflicts of Interest: The authors have no conflicts of interest to declare.

Ethical Statement: The authors are accountable for all aspects of the work in ensuring that questions related to the accuracy or integrity of any part of the work are appropriately investigated and resolved.

\section{References}

1. Donaldson K, Aitken R, Tran L, et al. Carbon nanotubes: a review of their properties in relation to pulmonary toxicology and workplace safety. Toxicol Sci 2006;92:5-22.

2. Shvedova AA, Kisin ER, Mercer R, et al. Unusual

Cite this article as: van Zandwijk N, Frank AL. Awareness: potential toxicities of carbon nanotubes. Transl Lung Cancer Res 2019;8(Suppl 4):S471-S472. doi: 10.21037/tlcr.2019.12.05 inflammatory and fibrogenic pulmonary responses to single-walled carbon nanotubes in mice. Am J Physiol Lung Cell Mol Physiol 2005;289:L698-708.

3. Grosse Y, Loomis D, Guyton KZ, et al. Carcinogenicity of fluoro-edenite, silicon carbide fibres and whiskers, and carbon nanotubes. Lancet Oncol 2014;15:1427-8.

4. Shvedova AA, Kisin E, Murray AR, et al. Inhalation vs. aspiration of single-walled carbon nanotubes in C57BL/6 mice: inflammation, fibrosis, oxidative stress, and mutagenesis. Am J Physiol Lung Cell Mol Physiol 2008;295:L552-65.

5. Baron PA, Deye GJ, Chen BT, et al. Aerosolization of single-walled carbon nanotubes for an inhalation study. Inhal Toxicol 2008;20:751-60.

6. Shvedova AA, Kisin ER, Murray AR, et al. Increased accumulation of neutrophils and decreased fibrosis in the lung of NADPH oxidase-deficient C57BL/6 mice exposed to carbon nanotubes. Toxicol Appl Pharmacol 2008;231:235-40.

7. Poland CA, Duffin R, Kinloch I, et al. Carbon nanotubes introduced into the abdominal cavity of mice show asbestos-like pathogenicity in a pilot study. Nat Nanotechnol 2008;3:423-8.

8. Harik VM. Geometry of carbon nanotubes and mechanisms of phagocytosis and toxic effects. Toxicol Lett 2017;273:69-85.

9. Stanton MF, Wrench C. Mechanisms of mesothelioma induction with asbestos and fibrous glass. J Natl Cancer Inst 1972;48:797-821.

10. IARC Monographs Priorities Group. Advisory Group recommendations on priorities for the IARC Monographs. Lancet Oncol 2019;20:763-4.

11. Marinaccio A, Binazzi A, Cauzillo G, et al. Analysis of latency time and its determinants in asbestos related malignant mesothelioma cases of the Italian register. Eur J Cancer 2007;43:2722-8.

12. Linton A, Vardy J, Clarke S, et al. The ticking timebomb of asbestos: its insidious role in the development of malignant mesothelioma. Crit Rev Oncol Hematol 2012;84:200-12. 